\title{
Effect of tiotropium on bronchial hyperreactivity and clinical and functional parameters in patients with chronic obstructive pulmonary disease
}

\begin{abstract}
Summary
The aim of this study was to investigate effects of tiotropium on bronchial hyperreactivity (BHR), clinical and functional parameters and quality of life in patients with chronic obstructive pulmonary disease (COPD).

Airway reactivity using inhaled metacholine challenge test (iMCT), clinical and functional status and quality of life were measured in 29 patients with moderate COPD. The patients were divided into 2 groups: those having positive iMCT (the $1^{\text {st }}$ group, $n=15 ; \mathrm{PC}_{20} \leq 0.471 \mathrm{mg}$ ) and those having negative iMCT (the $2^{\text {nd }}$ group, $n=14, \mathrm{PC}_{20}>0.471 \mathrm{mg}$ ). Effects of tiotropium on BHR were studied in an acute test and after 6-month treatment.

Reduction in BHR seen in the acute test was further maintained for 6-month therapy with tiptropium $(p<0.05)$. Decrease in BHR level to the end of 6-month treatment period was accompanied by a significant reduction in symptoms and exacerbation rate when compared to baseline parameters $(\mathrm{p}<0.05)$ and to parameters of patients without BHR as well. These processes were also accompanied by changes in FEV $\mathrm{F}_{1}$. An increase in prebronchodilator $\mathrm{FEV}_{1}$ in 6 months of treatment was $240 \mathrm{ml}$ in patients with BHR and $72 \mathrm{ml}$ in patients without BHR $(p<0.05)$. Quality of life improved by $10.0 \pm 4.2$ in patients with BHR vs patients without BHR $(p<0.05)$.

Therefore, therapy with tiotropium has led to positive changes in clinical and functional status of the patients and to a significant reduction in BHR. Patients with COPD and BHR were thought to be more responsible to tiotropium because they demonstrated more significant improvements in symptoms, exacerbation rate, $\mathrm{FEV}_{1}$ and quality of life when compared to those without BHR.

Key words: bronchial hyperreactivity, chronic obstructive pulmonary disease, tiotropium.
\end{abstract}

\section{Резюме}

Целью исследования было изучение влияния тиотропия на бронхиальную гиперреактивность (БГР), динамику клинико-функциональных показателей и качество жизни у пациентов с хронической обструктивной болезнью легких (ХОБЛ).

У 29 больных среднетяжелой ХОБЛ были изучены показатели реактивности бронхов в ингаляционном провокационном тесте с метахолином (ИПТм), клинико-функционального статуса и качества жизни. По результатам ИПТм пациенты были разделены на 2 группы: 1-я группа - пациенты $(n=15)$ с положительным тестом (ПД $20 \leq 0,471$ мг), 2 -я - $(n=14)$ с отрицательным тестом $\left(\Pi_{20}>0,471\right.$ мг). Влияние тиотропия на БГР изучалось в "острой" пробе и через 6 мес. лечения. Проведена сравнительная оценка клинико-функциональных показателей и качества жизни пациентов исходно и через 6 мес. терапии.

Снижение БГР, отмеченное в "острой" пробе, сохранялось через 6 мес.терапии тиотропием $(p<0,05)$. Снижение уровня БГР к концу лечебного периода сопровождалось значительным уменьшением выраженности симптомов и частоты обострений ХОБЛ как в сравнении с исходными параметрами $(p<0,05)$, так и показателями у пациентов без БГР. Этому соответствует динамика объема форсированного выдоха за 1-ю с $\left(\mathrm{OФB}_{1}\right)$. Прирост добронходилатационных значений ОФВ 1 через 6 мес. лечения составил в среднем 240 мл в группе больных с БГР и 72 мл - у пациентов без нее $(p<0,05)$. При сравнении показателей качества жизни отмечалось их улучшение у больных с БГР по сравнению с пациентами без БГР на $10,0 \pm 4,2$ балла $(p<0,05)$.

Таким образом, лечение тиотропием сопровождается положительной динамикой клинико-функционального статуса больных и существенным снижением БГР. Больные ХОБЛ с БГР более чувствительны к терапии тиотропием: у них в большей степени уменьшается выраженность симптомов и частота обострений, увеличиваются показатели ОФВ и качества жизни, по сравнению с пациентами без БГР. Ключевые слова: бронхиальная гиперреактивность, хроническая обструктивная болезнь легких, тиотропий.

Гиперреактивность дыхательных путей является высокочувствительным признаком бронхиальной астмы (БА) и рассматривается как один из основных предикторов и облигатных свойств этого заболевания $[1,2]$. Однако результаты современных исследований свидетельствуют о том, что бронхиальная гиперреактивность (БГР) характерна не только для БА, но и выявляется у 55-87 \% пациентов с хронической обструктивной болезнью легких (ХОБЛ) [3-5]. При этом эпидемиологические исследования, в т. ч. недавние, демонстрируют, что БГР является независи- мым предиктором развития ХОБЛ [6, 7] и вторым по значимости фактором риска этого заболевания, уступая только табакокурению [8]. Кроме того, БГР способна модифицировать течение ХОБЛ. В частности, у пациентов с данным фенотипом заболевания отмечаются больший темп снижения легочной функции [6], более выраженная одышка, меньшая толерантность к физической нагрузке, снижение качества жизни (КЖ) [5], неблагоприятный прогноз и повышенная летальность [9, 10], по сравнению с пациентами без БГР. 
Патогенетические механизмы БГР при ХОБЛ активно обсуждаются, но, скорее всего, как и при БА, они являются многокомпонентными. В отдельных исследованиях БГР связывают со степенью ограничения бронхиальной проходимости при ХОБЛ [11, 12], среди других наиболее вероятных механизмов указывают на воспаление, ремоделирование дыхательных путей и структурные изменения легочной паренхимы $[13,14]$. Кроме того, дефекты регуляции парасимпатического нейронального контроля гладкой мускулатуры респираторного тракта также рассматривают как фактор, инициирующий повышение бронхиальной реактивности $[15,16]$. Усиление парасимпатического влияния на фоне бронхолегочного воспаления, опосредованное активацией ацетилхолином мускариновых (М) рецепторов гладкой мускулатуры, способствует усилению бронхоконстрикторного ответа и развитию повышенной реактивности бронхов. В связи с этим назначение антихолинергических препаратов при бронхообструктивных заболеваниях, характеризующихся повышенным холинэргическим тонусом, рассматривается как патогенетически обоснованная терапия $[17,18]$. В частности, у больных БА ингаляция 10 мкг тиотропия вызывала снижение БГР, о чем свидетельствовало увеличение провокационной концентрации метахолина $\left(\Pi_{20}\right)$ более чем в 2 раза, тогда как увеличение дозы тиотропия до 40 мкг сопровождалось возрастанием ПК 20 в 7 раз [17]. При этом протективный эффект сохранялся на протяжении 48 ч. Результаты экспериментальных исследований также подтверждают бронхопротективный эффект антихолинергических препаратов. Так, использование антагонистов М3-холинорецепторов у мышей сопровождалось существенным снижением степени гиперчувствительности дыхательных путей и уровня биомаркеров воспаления в жидкости бронхоальвеолярного лаважа [19]. Вместе с тем данные о влиянии антихолинергических препаратов на БГР у больных ХОБЛ отсутствуют.

Целью настоящего исследования явилась оценка влияния 6-месячной терапии тиотропием на БГР и динамику клинико-функциональных показателей, включая КЖ, у больных ХОБЛ.

\section{Материалы и методы}

В исследование были включены 29 амбулаторных больных ХОБЛ средней степени тяжести в возрасте от 41 до 72 лет (средний возраст $-61,4 \pm 6,0$ года), из них 25 мужчин и 4 женщины. Диагностика ХОБЛ, включая оценку ее степени тяжести и обострений, осуществлялась на основании критериев Глобальной стратегии по хронической обструктивной болезни легких (GOLD) [20]. Все пациенты, в т. ч. экс-курильщики, имели индекс курения > 10 пачек / лет и для лечения ХОБЛ, как минимум в течение последних 3 мес., использовали только короткодействующие бронходилататоры по потребности.

Интенсивность респираторных симптомов оценивалась с использованием стандартизованных шкал: дневной и ночной кашель - по 5-балльной аналоговой шкале [21], одышка - по 4-балльной шкале MRC (Medical Research Council) [22]. Оценка показателей легочной функции проводилась на основании результатов спирометрии (Schiller Spirovit 1, Швейцария) исходно и после 400 мкг сальбутамола. Для исследования толерантности к физической нагрузке проводился 6-минутный шаговый тест (6-МШТ) в соответствии со стандартным протоколом, который включал в себя оценку пройденного расстояния (в метрах) и выраженность одышки в конце теста по 10-балльной аналогово-визуальной шкале Борга (0 - нет одышки, 10 - максимальная одышка) [22]. Анализ КЖ проводился с помощью специализированного вопросника St George's Respiratory Questionnaire (SGRQ) с оценкой доменов "Симптомы", "Активность", "Влияние" и общего КЖ (сумма).

У всех пациентов исследовалась реактивность бронхов в ингаляционном провокационном тесте (резервуарный метод) с метахолином (ИПТм) на оборудовании Pari Provotest 2 (Германия) [23]. В соответствии с протоколом первоначально ингалировался изотонический раствор $\mathrm{NaCl}$ с последующим проведением непосредственно провокационного теста с 0,33\%-ным раствором метахолина. Тест прекращался при падении показателя объема форсированного выдоха за 1-ю с $\left(\mathrm{OФB}_{1}\right) \geq 20 \%$ от исходного значения. БГР определялась на основании значения кумулятивной дозы метахолина (провокационная доза - ПД 20 ), вызывавшей снижение величины $\mathrm{OФB}_{1}$ на $\geq 20 \%$ от исходного показателя. В случае отсутствия снижения ОФВ $1 \geq 20 \%$ при ПД 20 , достигшей 0,471 мг, тест расценивался как отрицательный (отсутствие БГР), при снижении ОФВ $1 \geq 20 \%$ при ПД $20<0,471$ мг тест определялся как положительный, т. е. свидетельствующий о наличии БГР. В соответствии с протоколом метода уровень БГР расценивался как высокий при значениях ПД $20<0,04$ мг, средний - ПД 20 0,04-0,22 мг и низкий - ПД 20 0,23-0,47 мг. ПД 20 рассчитывали методом линейной интерполяции по общепринятой формуле [24].

Влияние тиотропия на БГР изучалось в 2 этапа. Первоначально проводилась "острая" проба, когда БГР (с учетом ПД 20 для метахолина) оценивалась до назначения тиотропия и через 60 мин после однократной ингаляции 18 мкг препарата. По результатам ИПТм пациенты были разделены на 2 группы: в 1-ю (БГР "+") вошли 15 человек с положительным тестом (ПД $20 \geq 0,471$ мг), во 2-ю (БГР"-") - 14 пациентов с отрицательным тестом (ПД $20>0,471$ мг).

На 2-м этапе у больных 1-й группы (БГР "+") повторно анализировались показатели реактивности бронхов (ПД 20 для метахолина) через 6 мес. лечения тиотропием (в интервале 24-26 ч после приема последней дозы препарата).

Кроме исходной оценки, перечисленные выше клинико-функциональные показатели и параметры КЖ определялись через 6 мес. лечения в обеих группах больных. Помимо этого, анализировалось число обострений в процессе лечения и за предшествующий 
Черняк Б.А., Трофименко И.Н. Влияние терапии тиотропием на бронхиальную гиперреактивность

6-месячный период. Статистическая обработка результатов проводилась с помощью методов вариационной статистики. Для сравнительного анализа использовались критерии Уилкоксона, Манна-Уитни.

\section{Результаты}

Исходная клиническая характеристика больных в зависимости от уровня БГР представлена в табл. 1. Как видно, больные в сравниваемых группах по большинству показателей, в том числе ОФВ 1 , существенно не различались. Однако интенсивность респираторных симптомов (кашель и одышка) была достоверно выше в группе больных с фенотипом БГР. Еще большей была разница по числу обострений: в предшествующие 6 мес. до лечения тиотропием у больных ХОБЛ с БГР обострения возникали в 2,9 раз чаще, чем у пациентов 2 -й группы $(p<0,01)$.

При оценке уровня реактивности дыхательных путей пациентов 1-й группы ПД 20 до назначения тиотропия составила $0,098 \pm 0,139$ мг. При этом у большинства пациентов (53 \%) выявлена высокая степень реактивности бронхов (ПД $20<0,04$ мг), $20 \%$ больных характеризовались средней степенью (ПД $20-0,04-0,22$ мг) и $27 \%-$ низкой БГР (ПД $20-$ 0,23-0,47 мг). Уровень реактивности бронхов существенно снижался уже через 60 мин после ингаляции 1-й дозы тиотропия: у 8 из 15 больных (53\%) ИПТм становился отрицательным, у больных же с сохранившимися признаками БГР величина ПД 20 возрастала более чем в 2,4 раза $(p<0,05)$. Высокая степень БГР, исходно имевшаяся у большинства больных, не выявлена ни в одном случае (рис. 1).

Очень важным обстоятельством является сохранность протективного эффекта тиотропия, зарегистрированного после однократной ингаляции препарата, на протяжении всего лечебного периода. Так, через 6 мес. терапии у 9 из 15 человек (60\%) ИПТм

Таблица 1

Клиническая характеристика больных

\begin{tabular}{|c|c|c|c|}
\hline Показатели & 1 -я группа $(n=15)$ & 2-я группа $(n=14)$ & $p$ \\
\hline Возраст, лет & $59,0 \pm 7,1$ & $63,2 \pm 4,7$ & 0,081 \\
\hline $\begin{array}{l}\text { Индекс курения, } \\
\text { пачек / лет }\end{array}$ & $36,8 \pm 15,6$ & $26,6 \pm 13,6$ & 0,114 \\
\hline Экс-курильщики, \% & 40,0 & 64,3 & 0,191 \\
\hline $\begin{array}{l}\text { Длительность ХОБЛ, } \\
\text { лет }\end{array}$ & $9,6 \pm 6,4$ & $5,2 \pm 1,8$ & 0,181 \\
\hline ИМТ, кг / м² & $26,4 \pm 9,3$ & $23,8 \pm 3,7$ & 0,055 \\
\hline Одышка, баллы & $2,1 \pm 0,5$ & $1,7 \pm 0,5$ & 0,187 \\
\hline Кашель, баллы & $2,7 \pm 0,5$ & $2,0 \pm 0,7$ & 0,035 \\
\hline ОФВ 1 до терапии, \% & $54,5 \pm 3,6$ & $57,5 \pm 5,4$ & 0,159 \\
\hline $\begin{array}{l}\text { ОФВ }{ }_{1} \text { после } \\
\text { терапии, \% }\end{array}$ & $65,0 \pm 5,7$ & $65,9 \pm 7,4$ & 0,843 \\
\hline 6-МШТ, м & $434,8 \pm 72,4$ & $454,6 \pm 50,6$ & 0,598 \\
\hline $\begin{array}{l}\text { Одышка по шкале } \\
\text { Борга, баллы }\end{array}$ & $3,8 \pm 0,6$ & $2,8 \pm 0,4$ & 0,002 \\
\hline $\begin{array}{l}\text { Частота обострений } \\
\text { ХОБЛ за } 6 \text { мес. }\end{array}$ & $0,9 \pm 0,5$ & $0,3 \pm 0,3$ & 0,003 \\
\hline $\begin{array}{l}\text { Общая оценка КЖ } \\
\text { (SGRQ), баллы }\end{array}$ & $42,0 \pm 17,0$ & $32,7 \pm 16,9$ & 0,187 \\
\hline
\end{tabular}

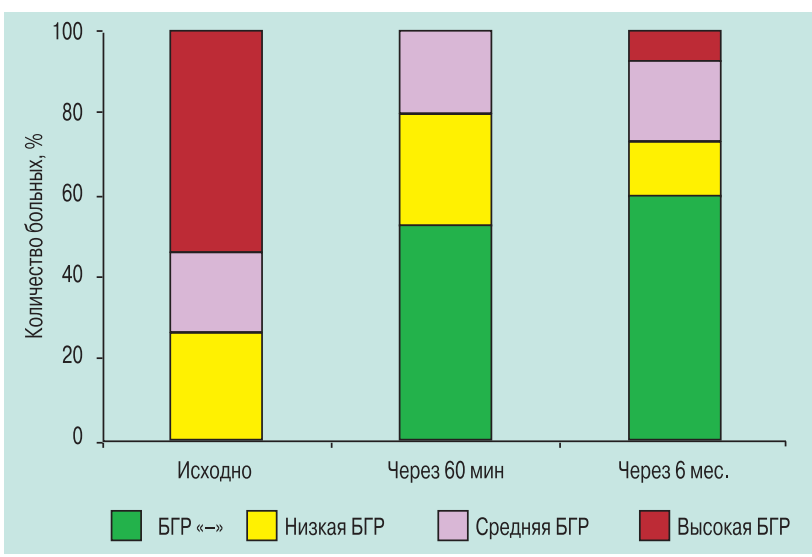

Рис. 1. Динамика уровня бронхиальной реактивности в процессе лечения тиотропием

был отрицательным (ПД $20>0,471$ мг). При этом у абсолютного большинства больных (7 из 8 пациентов) с отрицательным тестом после тиотропия в "острой" пробе, через 6 мес. терапии также не выявлено БГР. У остальных пациентов сохранялось значительное снижение уровня БГР (рис. 1), о чем свидетельствует достоверное повышение ПД 20 метахолина до 0,121 \pm 0,112 мг $(p<0,05)$ относительно исходного уровня.

Оценка показателей клинико-функционального статуса и КЖ в процессе 6-месячного лечения показала существенную положительную динамику в обеих группах больных ХОБЛ. Вместе с тем имеются отчетливые особенности ответа на терапию тиотропием у пациентов с БГР (табл. 2 и 3). В частности, снижение уровня БГР у больных 1-й группы сопровождается выраженным уменьшением одышки $(p<0,05)$, тогда как во 2-й группе различия между исходными значениями и показателями через 6 мес. достоверно не изменились. Взаимосвязь между степенью одышки (MRC) и уровнем БГР (ПД 20 метахолина) в процессе лечения подтверждается и кор-

Таблииа 2 Динамика выраженности симптомов ХОБЛ

\begin{tabular}{|lc|c|c|c|}
\multicolumn{2}{c|}{ Симптомы } & Исходно & 6 мес. & $p$ \\
Одышка & БГР "+" & $2,1 \pm 0,5$ & $1,5 \pm 0,8$ & 0,048 \\
\hline \multirow{2}{*}{ Кашель днем } & БГР "-" & $1,7 \pm 0,5$ & $1,3 \pm 0,5$ & 0,069 \\
& БГР "+" & $2,7 \pm 0,5$ & $1,7 \pm 0,7$ & 0,007 \\
Кашель ночью & БГР "-" & $2,0 \pm 0,7$ & $1,2 \pm 0,4$ & 0,028 \\
& БГР "+" & $0,9 \pm 0,8$ & $0,3 \pm 0,7$ & 0,027 \\
& БГР "-" & $0,4 \pm 0,8$ & $0,6 \pm 0,8$ & 0,753
\end{tabular}

Таблица 3 Динамика показателей КЖ

\begin{tabular}{l|c|c|c|c} 
Домены (SGRQ) & Группы & Исходно & 6 мес. & $p$ \\
\hline Симптомы & БГР "+" & $57,3 \pm 23,9$ & $37,4 \pm 17,1$ & 0,005 \\
& БГР "-" & $48,4 \pm 24,6$ & $33,4 \pm 11,8$ & 0,036 \\
Активность & БГР "+" & $48,6 \pm 15,9$ & $35,0 \pm 16,9$ & 0,002 \\
& БГР "-" & $40,2 \pm 17,9$ & $36,8 \pm 15,6$ & 0,575 \\
Влияние & БГР "+" & $33,3 \pm 17,3$ & $16,4 \pm 14,1$ & 0,008 \\
& БГР "-" & $25,4 \pm 18,9$ & $19,7 \pm 11,5$ & 0,327 \\
Общее КЖ & БГР "+" & $42,0 \pm 17,0$ & $25,5 \pm 14,2$ & 0,001 \\
& БГР "-" & $32,7 \pm 16,9$ & $26,2 \pm 11,6$ & 0,399
\end{tabular}




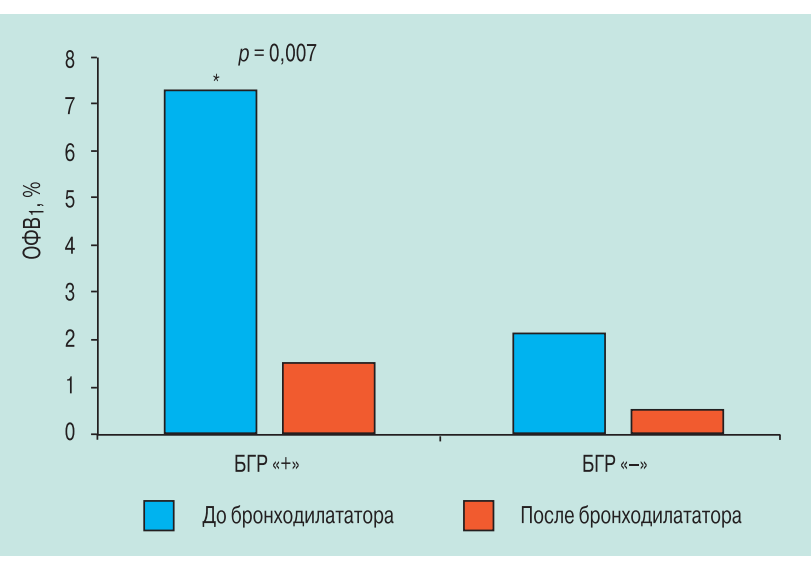

Рис. 2. Динамика прироста ОФВ 1 до и после бронходилататора через 6 мес. лечения тиотропием у больных ХОБЛ в зависимости от наличия БГР

Примечание: * $-p<0,05$ в сравнении с больными без БГР

реляционным анализом, показывающим выраженную обратную зависимость для этих показателей: $r s=-0,67(p<0,05)$. Аналогичная закономерность имеет место и при кашле. Особенно отчетливо она выражена при ночном кашле: у больных без БГР его интенсивность существенно не меняется, а у пациентов с БГР - значимо снижается $(p<0,05)$.

Отмеченной динамике респираторных симптомов соответствуют и изменения показателей бронхиальной обструкции. У больных ХОБЛ с БГР через 6 мес. терапии тиотропием ОФВ 1 была достоверно выше не только в сравнении с исходными параметрами, но и по сравнению с показателями ФВД у пациентов 2-й группы (рис. 2). Так, прирост добронходилатационных значений ОФВ 1 через 6 мес. лечения составил в среднем 240 мл у больных с БГР и только 72 мл у пациентов без БГР ( $p<0,05)$. Аналогичная тенденция отмечается и при сравнении постбронходилатационных показателей: увеличение ОФВ 1 в 1-й группе составило в среднем 46 мл и во 2-й группе больных -18 мл $(p>0,05)$.

Через 6 мес. лечения в обеих группах отмечалось значительное улучшение толерантности к физической нагрузке: пройденное расстояние в 6-МШТ возросло в среднем на 27 м в 1-й группе и 41 м - во 2-й $(p<0,05)$; одышка по шкале Борга снизилась на 1 балл относительно исходных показателей $(p<0,01)$ в обеих группах, однако статистически значимые межгрупповые различия отсутствовали.

Анализ частоты обострений ХОБЛ на протяжении лечебного периода, напротив, выявил достоверные различия между пациентами в зависимости от уровня БГР. Так, количество обострений в группе больных с БГР снизилось по сравнению с исходными показателями в 3,4 раза $(0,86$ и 0,25 соответственно; $p=0,005)$, тогда как во 2-й группе частота обострений существенно не изменилась $(0,3$ и 0,4 соответственно; $p>0,1)$. Наличие взаимосвязи между уровнем БГР и частотой обострений подтверждается и результатами корреляционного анализа, согласно которому коэффициент корреляции (rs) между ПД 20 и числом обострений у больных с БГР составляет $-0,61(p<0,05)$, что еще раз демонстриру- ет негативное влияние БГР на клиническое течение ХОБЛ.

Наибольшие различия в ответе на длительную терапию тиотропием в сравниваемых группах были получены при оценке КЖ (табл. 3). Анализ параметров КЖ у больных с БГР показал значительное улучшение в сравнении с исходными значениями на 14-20 баллов по всем доменам вопросника $(p<0,01)$ У больных ХОБЛ без БГР терапия тиотропием сопровождалась гораздо меньшим улучшением показателей КЖ: статистически значимые различия по сравнению с исходными параметрами получены только для домена "Симптомы" $(p<0,05)$. Межгрупповое сравнение показывает лучшую динамику показателей КЖ у больных с БГР по таким доменам, как "Активность", "Влияние" и "Общее качество жизни".

\section{Обсуждение}

Имеющиеся научные данные свидетельствуют о том, что БГР, являясь одним из ведущих факторов риска формирования ХОБЛ, способна модифицировать течение заболевания [5-9]. В частности, фенотипический вариант ХОБЛ с БГР характеризуется более ранним развитием и тяжелым течением, частыми обострениями и быстро прогрессирующими обструктивными нарушениями, что в конечном счете обусловливает и более высокую смертность в этой группе больных [10]. В предыдущих исследованиях было показано, что даже при нетяжелых функциональных нарушениях $\left(\mathrm{OФB}_{1}>50 \%\right)$ БГР у больных ХОБЛ ассоциируется с большей выраженностью одышки, более частыми обострениями, меньшей толерантностью к физической нагрузке и более низкими показателями КЖ [5]. В связи с этим возникают два вопроса: влияет ли бронхолитическая и, в частности, антихолинергическая терапия на БГР у больных ХОБЛ и, если влияет, то имеет ли это какое-то клинико-функциональное значение? Результаты проведенного исследования позволяют положительно ответить на оба вопроса.

Полученные результаты свидетельствуют, что даже однократное введение терапевтической дозы тиотропия сопровождается значительным снижением уровня БГР. При этом тиотропий в > 1/2 случаев предотвращает бронхоконстрикцию в ответ на максимально допустимую, согласно протоколу, кумулятивную дозу метахолина. Важным для клиники представляется тот факт, что снижение БГР, или, другими словами, протективный эффект тиотропия, регистрируемый в "острой" пробе, сохраняется при его ежедневном применении как минимум в течение 6 мес., т. е. на протяжении всего лечебного периода. Количество пациентов, не отвечающих бронхоконстрикцией на ингаляцию метахолина, не только не снизилось, но даже увеличилось. В то же время у $40 \%$ больных с сохранившейся БГР ее уровень был достоверно ниже по сравнению с исходными показателями. В настояшее время хорошо известно, что благодаря брохолитическому действию тиотропий 
Черняк Б.А., Трофименко И.Н. Влияние терапии тиотропием на бронхиальную гиперреактивность

подавляет эффект тахифилаксии - влоть до полного отсутствия. Показано, что многолетнее применение этого препарата не сопровождается снижением бронхолитческой активности [25]. Полученные данные позволяют предположить, что тахифилаксия при длительном использовании тиотропия не развивается и в отношении его бронхопротективного эффекта. Вместе с тем не только отсутствие снижения бронхопротективного действия, но и его увеличение при длительном применении тиотропия, возможно, связано с кумулятивным противовоспалительным эффектом антихолинергических препаратов [19].

Снижение уровня БГР оказывает существенное клиническое влияние на течение ХОБЛ, что видно из результатов оценки 6-месячного терапевтического эффекта тиотропия в 2 сравниваемых группах. Как оказалось, терапевтический ответ на тиотропий характеризовался определенными различиями у больных в зависимости от фенотипических особенностей ХОБЛ. Так, антихолинергическая терапия сопровождалась достоверно более выраженным увеличением ОФВ 1 , по сравнению с исходными значениями, в группе больных с БГР. Более заметное уменьшение у больных с БГР таких респираторных симптомов, как одышка и кашель, соответствовало динамике функциональных показателей. Частота обострений, являющаяся одной из важных характеристик эффективности лечения ХОБЛ, также ассоциировалась с уровнем БГР: если в 1-й группе больных на фоне лечения тиотропием число обострений достоверно снизилось, то у больных ХОБЛ без БГР оно существенно не изменилось. И, наконец, КЖ параметр, позволяющий интегрально оценить состояние больного, также характеризовался высоко достоверными различиями между группами в процессе лечения. Больные в группе ХОБЛ с БГР демонстрировали гораздо лучший ответ на терапию тиотропием по всем доменам специализированного вопросника.

Таким образом, БГР, являясь фенотипическим маркером одного из вариантов ХОБЛ, ассоциируется не только с клиническими и функциональными особенностями заболевания, более тяжелым течением и неблагоприятным прогнозом, но и с особенностями ответа на антихолинергическую терапию. Исследования экспрессии генов М3-холинорецепторов в бронхах, выполненные совместно с группой ученых из Томска, выявили генотипическую гетерогенность ХОБЛ [26]. В частности, было показано, что уровень экспрессии генов М3-холинорецепторов в бронхиальном дереве у больных среднетяжелой ХОБЛ при наличии БГР достоверно выше по сравнению с аналогичными больными, но не имеющими БГР.

Эти данные позволяют предположить, что основой фенотипа ХОБЛ с БГР является высокий уровень экспрессии М3-холинорецепторов, что и определяет ранее отмеченные особенности терапевтического ответа в данной группе больных на тиотропий - высокоселективный антихолинергический препарат.

\section{Заключение}

Полученные результаты, а также данные специальной литературы позволяют рассматривать БГР не только как маркер неблагоприятного прогноза и тяжелого течения ХОБЛ. БГР может служить патогенетическим и фенотипическим параметром заболевания, обусловливающим вариабельность клинических проявлений и терапевтического ответа. Длительное применение тиотропия оказывает положительное терапевтическое действие независимо от клинического варианта ХОБЛ, однако эффективность лечения является наиболее высокой у пациентов с БГР.

\section{Литература}

1. Global Strategy for Asthma Management and Prevention, Global Initiative for Asthma. UPDATED 2011. www.ginasthma.org

2. Barnes P.J. Mechanisms in COPD. Differences from asthma. Chest 2000; 117: 10-14.

3. Kanner R.E., Connett J.E., Altose M.D. et al. Gender difference in airway hyperresponsiveness in smokers with mild COPD. The Lung Health Study. Am. J. Respir. Crit. Care Med. 1994; 150 (4): 956-961.

4. Yang S.C., Lin B.Y. Comparison of airway hyperreactivity in chronic obstructive pulmonary disease and asthma. Chang Gung Med. J. 2010; 33: 515-523.

5. Трофименко И.Н., Черняк Б.А. Бронхиальная гиперреактивность как фенотипическая характеристика хронической обструктивной болезни легких. Пульмонология 2011; 4: 49-53.

6. Brutsche M.H., Downs S.H., Schindler C. et al. Bronchial hyperresponsiveness and the development of asthma and COPD in asymptomatic individuals: SAPALDIA Cohort Study. Thorax 2006; 61: 671-677.

7. Xu X., Rijcken B., Schouten J.P. et al. Airways responsiveness and development and remission of chronic respiratory symptoms in adults. Lancet 1997; 350: 1431-1434.

8. De Marco R., Accordini S., Marcon A. et al. Risk factors for chronic obstructive pulmonary disease in a European cohort of young adults. Am. J. Respir. Crit. Care Med. 2011; 183 (7): 891-897.

9. Tashkin D.P., Altose M.D., Connett J.E. et al. Methacholine reactivity predicts changes in lung function over time in smokers with early chronic obstructive pulmonary disease. The Lung Health Study Research Group. Am. J. Respir. Crit. Care Med. 1996; 153: 1802-1811.

10. Hospers J.J., Postma D.S., Rijcken B. et al. Histamine airway hyper-responsiveness and mortality from chronic obstructive pulmonary disease: a cohort study. Lancet 2000; 356: 1313-1317.

11. Grootendorst D.C., Rabe K.F. Mechanisms of bronchial hyperreactivity in asthma and chronic obstructive pulmonary disease. Proc. Am. Thorac. Soc. 2004; 1: 77-87.

12. Wise R.A., Kanner R.E., Lindgren P. et al. The effect of smoking intervention and an inhaled bronchodilator on airways reactivity in COPD: the Lung Health Study. Chest 2003; 124: 449-458.

13. Postma D.S., Kerstjens H.A.M. Characteristics of airway hyperresponsiveness in asthma and chronic obstructive pulmonary disease. Am. J. Respir. Crit. Care Med. 1998; 158: 187-192. 
14. Lancas T., Kasahara D.I., Gross J.L. et al. Cholinergic hyperresponsiveness of peripheral lung parenchyma in chronic obstructive pulmonary disease. Respiration 2011; 82: $177-184$

15. Fisher J.T., Vincent S.G., Gomeza J. et al. Loss of vagally mediated bradycardia and bronchoconstriction in mice lacking M2 or M3 muscarinic acetylcholine receptors. FASEB J. 2004; 18 (6): 711-713.

16. Belmonte K.E. Cholinergic pathways in the lungs and anticholinergic therapy for chronic obstructive pulmonary disease. Proc. Am. Thorac. Soc. 2005; 2: 297-304.

17. O'Connor B.J., Towse L.J., Barnes P.J. Prolonged effect of tiotropium bromide on methacholine-induced bronchoconstriction in asthma. Am. J. Respir. Crit. Care Med. 1996; 154: 876-880.

18. Gosens R., Zaagsma J., Meurs H. et al. Muscarinic receptor signaling in the pathophysiology of asthma and COPD. Respir. Res. 2006; 7 (1): 73.

19. Cao R., Dong X.W., Jiang J.X. et al. M (3) muscarinic receptor antagonist bencycloquidium bromide attenuates allergic airway inflammation, hyperresponsiveness and remodeling in mice. Eur. J. Pharmacol. 2011; 655: 83-90.

20. Global Strategy for the Diagnosis, Management, and Prevention of Chronic Obstructive Pulmonary Disease, Global Initiative for Chronic Obstructive Lung Disease (GOLD) 2011. www.goldcopd.org
21. Gulsvik A., Refvem O.K. Ascoring system on respiratory symptoms. Eur. Respir. J. 1988; 1: 428-432.

22. Чучалин А.Г. (ред.). Пульмонология. Клинические рекомендации. М.: ГЭОТАР-Медиа; 2005. 212-213.

23. Klein G., Köhler D., Bauer C.P. et al. Standartization of inhalation chal-lenges for measuring the unspecific bronchial inhalation challenge by re-servuar-method. Pneumologie 1991; 45: 60-64.

24. Стандартизация легочных функциональных тестов: Пер. с англ. под ред. А.Г.Чучалина. М.; 1993. 68-69.

25. Troosters T., Celli B., Lystig T. et al. Tiotropium as a first maintenance drug in COPD: secondary analysis of the UPLIFT® ${ }^{\circledR}$ trial. Eur. Respir. J. 2010; 36 (1): 65-73.

26. Selivanova P.A., Kulikov E.S., Kozina O.V. et al. Differential expression of the $\beta_{2}$-adrenoreceptor and M3-cholinoreceptor genes in bronchial mucosa of patients with asthma and chronic obstructive pulmonary disease. Ann. Allergy Asthma Immunol. 2012; 108: 39-43.

\section{Информация об авторах}

Черняк Борис Анатольевич - д. м. н., проф., зав. кафедрой клинической аллергологии и пульмонологии Иркутской государственной медицинской академии последипломного образования; тел.: 8-902-568-78-70; e-mail: bores@angara.ru

Трофименко Ирина Николаевна - к. м. н., ассистент кафедры клинической аллергологии и пульмонологии Иркутской государственной медицинской академии последипломного образования; тел.: 8-914877-80-96; e-mail: tin11@mail.ru 